\title{
Academic standards in Italy
}

SIR - G. F. Gaetani and A. M. Ferraris (Nature 353, 10; 1991) examined the proceedings of a committee set up by the Italian Ministry of University, Scientific Research and Technology (MURST) to evaluate the scientific achievements of candidates for full professorship in a particular branch of medicine. They were perplexed that the proceedings did not mention the criteria used for evaluation, nor the adoption of a scale of values or of internationally accepted scientific indicators.

The indicators proposed by Gaetani and Ferraris were later criticized by $S$. Amadori et al. $(\mathbf{3 5 5}, 581 ; 1991)$ as possibly misleading, while the committee in question volunteered some explanations of the criteria adopted (M. Baccarani et al. 356, 188; 1992), whose extravagance, in view of the existing Italian laws, was pointed out by F. Aiuti (356, 556; 1992).

I should like to present evidence that no scale of values for scientific achievement is normally adopted in Italian university competitions for professorships, so that, with the full knowledge and approval of MURST, selection for academic promotion has become increasingly arbitrary and less and less dependent on the scientific accomplishments of the candidates. The evidence is taken from the official proceedings of a recent national competition for tenured positions at the level of associate professor in theoretical and mathematical physics, and thus lends support to the suggestion by G. Visconti (356, 188; 1992) that the present machinery for academic promotion in Italy produces adverse effects well beyond the boundaries of the faculty of medicine, contrary to the belief of F. Aiuti et al. $(356,188 ; 1992)$ that it produces good results in physics.

In June 1991, a committee of nine theoretical physicists (five full and four associate professors) was set up and several meetings were held during the following few months to reduce the number of applicants to about a third of the original 150.

On 21 November 1991, one member of the committee remarked that even the vague guidelines issued by MURST implied comparison of the scientific achievements of the candidates, in view of the final selection of 14 winners, and proposed the adoption of criteria for making such a comparison. The rest of the committee objected that evaluation of scientific achievement could not be a matter of 'mechanical' procedures; by a majority of eight to one they turned down the proposal and approved a resolution on 16 December 1991 emphasizing the freedom of judgement of the individual committee members.
To clarify the apparent contradiction between the adoption of quantitative indicators and freedom of judgement, the dissenting member then proposed that these indicators be considered together with other criteria (with relative weights to be agreed later) without prejudice to the freedom of judgement of individual committee members. The president of the committee refused to put this to the vote, and officially accused the dissenting member of obstruction. The question, of course, was not about the nature of any particular indicator but whether quantitative criteria should be adopted. It was clearly the opinion of all but one of the committee that preliminary agreement on a scale of values was inappropriate or superfluous.

Between December 1991 and February 1992, the dissenting member wrote three times to the minister, explaining the situation and asking for a clear statement of whether the adoption of quantitative criteria for the evaluation of scientific achievement was permissible or not. The only response from the minister was a telegram of dismissal from the committee on 18 February 1992.

The case illustrates important aspects of the generalized practice in Italy for academic promotion, and also provides a solution to Gaetani and Ferraris's puzzle on the criteria used to evaluate scientific achievements. It also shows that academic authorities at the highest level are fully aware of the prevailing practice.

\section{F. Persico}

\section{Istituto di Fisica}

dell'Università degli Studi,

Via Archirafi, 36 ,

1-90123 Palermo, Italy

SIR - The proposals of Professor David Burr (Nature 357, 273; 1992) for improving the performance of Italian universities make only brief mention of an all-important need, "linking university funding to performance", a point on which one needs to be more explicit. In fact, an increase in the autonomy of the universities, particularly in assigning faculty positions, could be misused by powerful local lobbies in the absence of rigorous evaluation mechanisms for sharing out financial and other public resources.

The absence in Italy of adequate evaluation processes not only for teaching and research in universities but also in many areas of nonacademic science has long been bemoaned both nationally and internationally. In the face of strenuous opposition by interested parties, however, the remedies so far adopted are little more than palliatives. Given these precedents and the present political situation, the remedies we need, such as the creation of strong advisory bodies with extensive international participation, are unlikely to be forthcoming in the foreseeable future.

In the meantime, problems such as those mentioned previously by Eugenio Tabet and myself (see Nature 348, 104; 1990) can only get worse. For example, competition for research funds is becoming more frantic because of an increase in public funding for industrial research and development, at least in certain areas. This political decision and the resulting decrees of the Minister of Universities and Research - for example, the recent one soliciting applications by industry consortia for the assignment of 108 billion lira (about $£ 50$ million) for neurobiological research - means that research groups at public institutions must beg for subcontracts from private parties, as a substitute for an evaluationbased financing by less devious pathways.

\section{Giorgio Bignami}

Istituto Superiore di Sanitá,

Viale Regina Elena 299,

1-00161 Roma, Italy

\section{Peer review}

SIR - Peer review (Nature 357, 354; 1992) has its strengths but it is not perfect. Its weakness is its strength - its susceptibility to feedback.

Peer review is like a black box, the input to which is the attempts of scientists to get published, the output from which is the material that gets published. The black box contains everything necessary for positive and negative feedback.

Neither sort of feedback is here automatically good or automatically bad, it depends on the ends the feedback obtains - and on one's view of what is desirable. The ends run from suppression of an article - or subject through modification to encouragement. Feedback applied to any given article is, a priori, as likely to benefit the reviewer as it is the author, as likely to benefit the reviewer as it is the readership, as likely to benefit the reviewer as it is mankind.

To say that something possesses a capacity is not, however, to say that that thing makes continual and untrammelled use of that capacity. It does not automatically follow that either sort of feedback current flows in any one instance of the peer review circuit. The resistance preventing current flowing - or preventing an undesirable sort or amount of current flowing - seems simply to be constituted by the judgement of the individuals concerned.

\section{J. A. Negus}

Bessas,

07150 Vallon Pont d'Arc, France 